EPJ Web of Conferences 98, 08001 (2015)

DOI: $10.1051 /$ epjconf/ 20159808001

C) Owned by the authors, published by EDP Sciences - SIF, 2015

\title{
Functional materials for energy-efficient buildings
}

\author{
H.-P. $\operatorname{EBERT}(*)$ \\ ZAE Bayern, Bavarian Center for Applied Energy Research \\ Am Galgenberg 97, 97074 Würzburg, Germany
}

\begin{abstract}
Summary. - The substantial improving of the energy efficiency is essential to meet the ambitious energy goals of the EU. About $40 \%$ of the European energy consumption belongs to the building sector. Therefore the reduction of the energy demand of the existing building stock is one of the key measures to deliver a substantial contribution to reduce $\mathrm{CO}_{2}$-emissions of our society. Buildings of the future have to be efficient in respect to energy consumption for construction and operation. Current research activities are focused on the development of functional materials with outstanding thermal and optical properties to provide, for example, slim thermally superinsulated facades, highly integrated heat storage systems or adaptive building components. In this context it is important to consider buildings as entities which fulfill energy and comfort claims as well as aesthetic aspects of a sustainable architecture.
\end{abstract}

\section{1. - Thermal insulation}

Thermal insulation of buildings is one of the most effective ways to save energy resources for heating and cooling and providing comfortable temperatures in living and working rooms. The physical principle behind these efforts which were empirically optimised with time and passed down generations is to generate a volume of still air within

$\left(^{*}\right)$ E-mail: hans-peter.ebert@zae-bayern.de

This is an Open Access article distributed under the terms of the Creative Commons Attribution License 4.0, which permits unrestricted use, distribution, and reproduction in any medium, provided the original work is properly cited. 


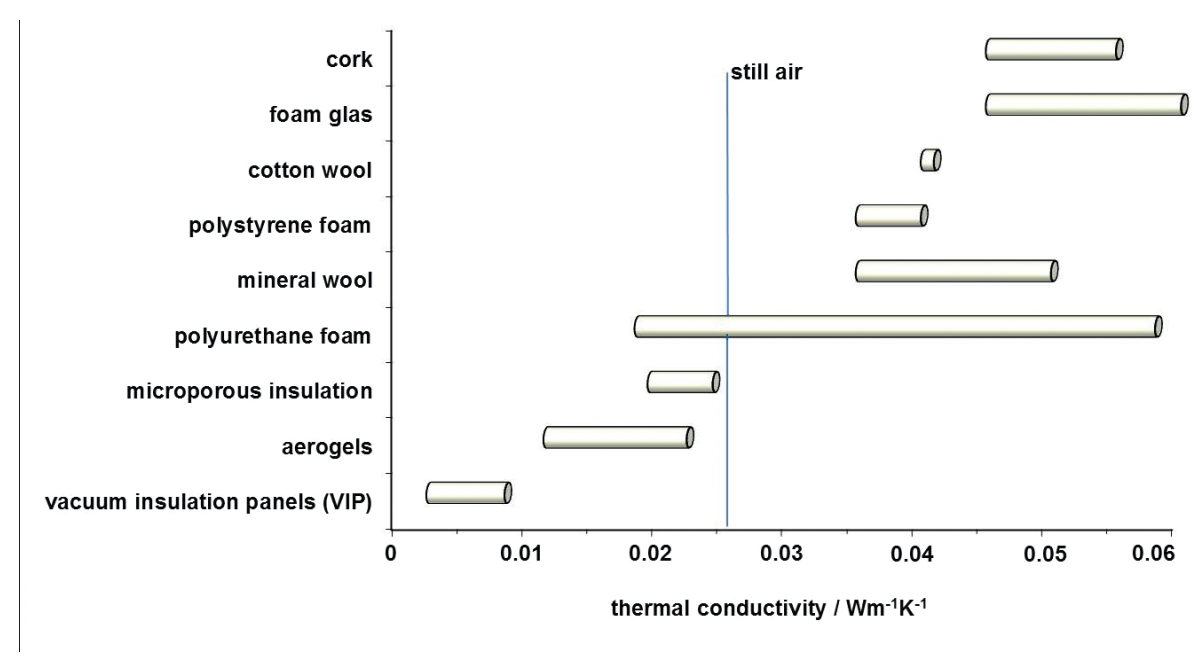

Fig. 1. - Typical thermal conductivity values of thermal insulation materials at ambient conditions.

a porous structure and to avoid convection effects. Thus the thermal conductivity of still air, i.e. $0.026 \mathrm{Wm}^{-1} \mathrm{~K}^{-1}$ at ambient conditions comes significantly into effect and provides a reasonable thermal insulation. Thermal insulation materials or systems which show effective thermal conductivity values far below the conductivity value of still air at ambient conditions are known as so called superinsulations. An overview of thermal insulation materials are depicted in fig. 1.

Within a porous insulation material heat is transported by three different mechanisms: conductive heat transfer via the solid backbone, heat conduction within the gas phase and radiative heat transfer (cf. fig. 2). Convection, i.e. the transport of energy by free or forced convective gas flow, does not occur in thermal insulations because of the limited free space, the relatively low temperature and nonexistent pressure differences in building applications.

The thermal insulation properties of an insulation material are determined by the total effective thermal conductivity $\lambda_{\text {eff }}$, which is a temperature-dependent material property and is defined by Fourier's law. The total effective thermal conductivity could be described in a good approximation by the sum of the solid thermal conductivity, $\lambda_{\mathrm{s}}$, the thermal conductivity of the gas within a given porous structure, $\lambda_{\mathrm{g}}$, and the radiative thermal conductivity, $\lambda_{\mathrm{r}}$, which reflects the involved heat transfer mechanisms [1]:

$$
\lambda_{\text {eff }}\left(T, p_{g}\right)=\lambda_{s}(T)+\lambda_{g}\left(T, p_{g}\right)+\lambda_{r}(T),
$$

with $T$ the temperature and $p_{g}$ the gas pressure.

In fig. 3 the gas pressure-dependent thermal conductivity of typical insulation materials are depicted. For materials like glass fibres and foams with large pores in comparison to the mean free path of the gas molecules (for nitrogen at ambient conditions about 


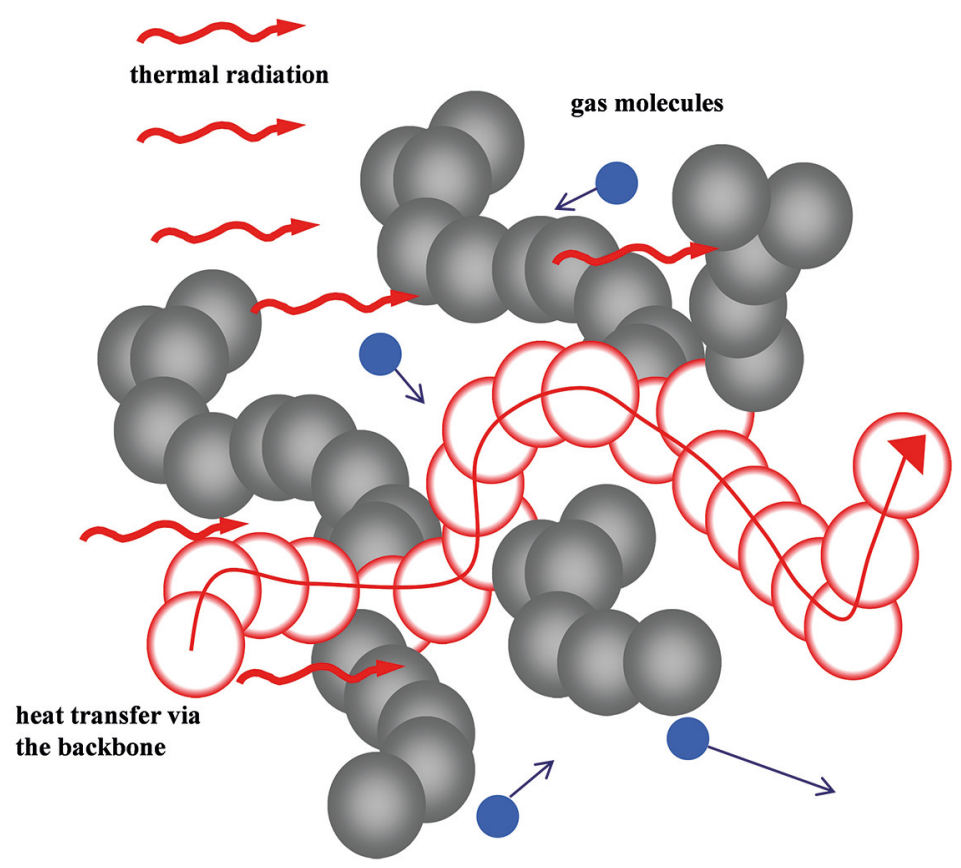

Fig. 2. - Heat transfer mechanisms within thermal insulations. Heat transfer takes place by heat conduction via the solid skeleton and the gas phase and by thermal radiation.

$70 \mathrm{~nm}$ ), the saturation region where the diffusive heat transfer occurs can be clearly observed for gas pressures above 10 mbar. Here the thermal conductivity is nearly independent of gas pressure. For microporous materials, like precipitated and fumed silica with pore sizes in the range of the mean free path of nitrogen, the thermal conductivity of the pore gas is already reduced and a total effective thermal conductivity below or in the range of the thermal conductivity of still air could be seen. The thermal conductivity values for the gas pressure independent regime at low gas pressures indicate the sum of the solid thermal and radiative conductivity, $\lambda_{\mathrm{s}}+\lambda_{\mathrm{r}}$.

From fig. 3 also two obvious directions for the realisation of superinsulation could be recognised. Firstly, the possibility to evacuate porous insulations would lead to effective thermal insulation systems with thermal conductivity values about 10 times lower as they are known for conventional insulation materials. This effect leads to the development of vacuum insulation panels for building applications [2-4]. Secondly, the reduction of pore size below $1 \mu \mathrm{m}$ would have the effect that even at ambient conditions thermal insulation products would have thermal conductivity values below those of still air.

For flat vacuum insulation panels which are applicable for building insulation a microporous kernel is used which consists of a pressed silica powder in the most cases (cf. fig. 4). Additionally an infrared opacifier is added to the silica powder to reduce the radiative heat transfer. The pressed silica core is embedded in a core bag to enable a further dustless manufacturing of the final VIP. The filled core bag will be enfolded by a multi- 


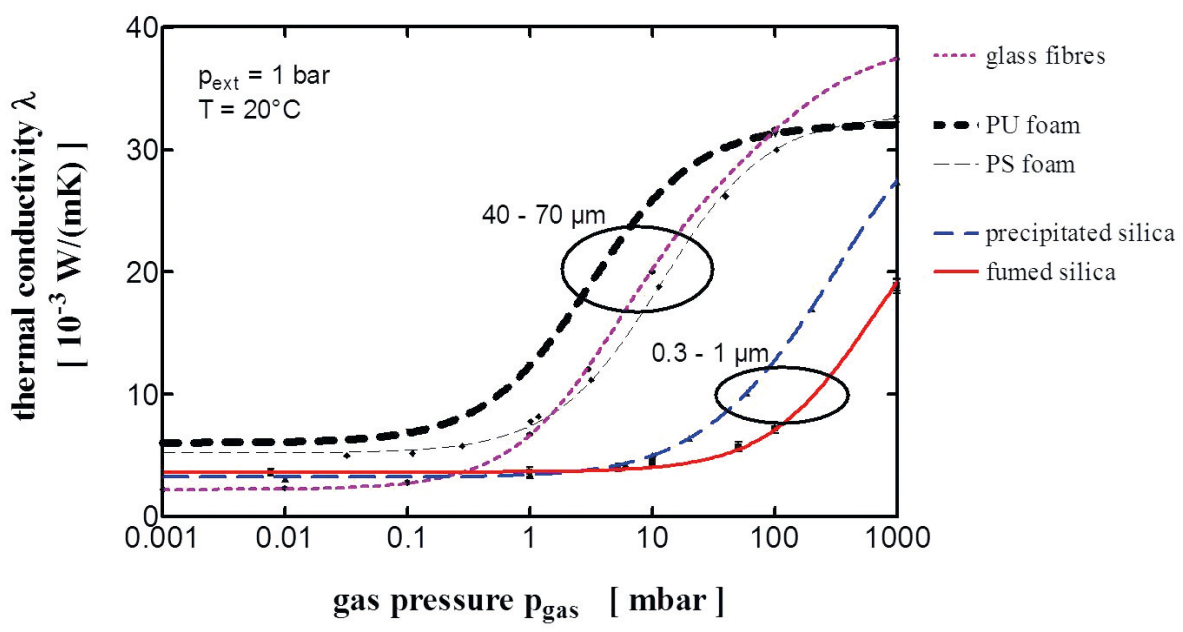

Fig. 3. - Thermal conductivity of porous insulation materials as a function of gas pressure for an external load of $1 \mathrm{bar}$ and at $20^{\circ} \mathrm{C}$. The typical range of the average pore size of the investigated materials is also given.

layer envelope film. This package will be evacuated down to 1 mbar and sealed within a vacuum chamber. The advantage of a kernel made of fumed silica which is evacuated at gas pressure of about 1 mbar could be seen in fig. 3. While for conventional insulation kernels like glass fibres or foams the effective thermal conductivity would immediately increase with gas pressure at a gas pressure of $1 \mathrm{mbar}$, for the microporous fumed silica

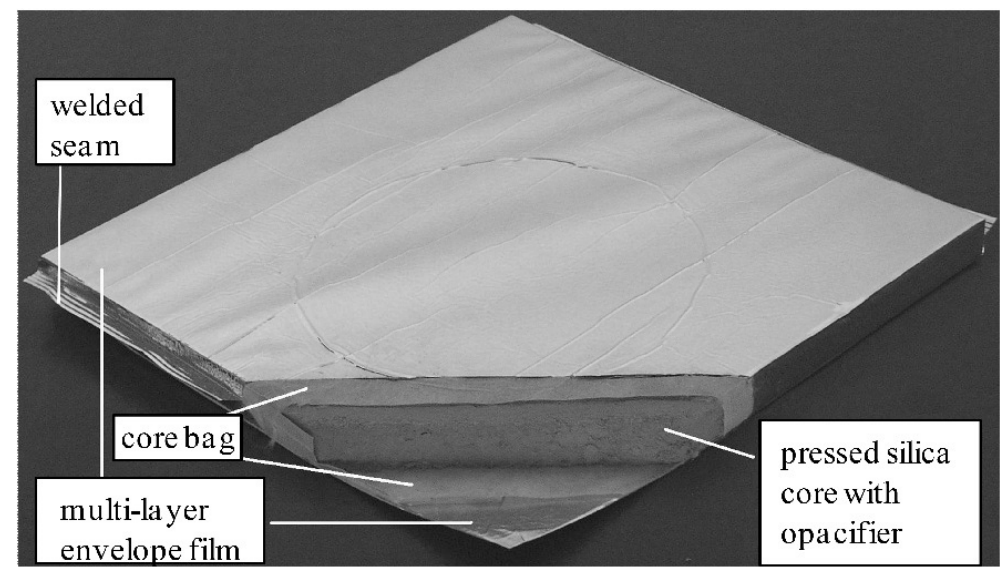

Fig. 4. - Construction of a vacuum insulation panel (VIP) used for building insulation: a pressed silica core is embedded in a core bag to enable a further dustless manufacturing of the final VIP. The filled core bag will be enfolded by a multi-layer envelope film. This package will be evacuated and sealed within a vacuum chamber. 


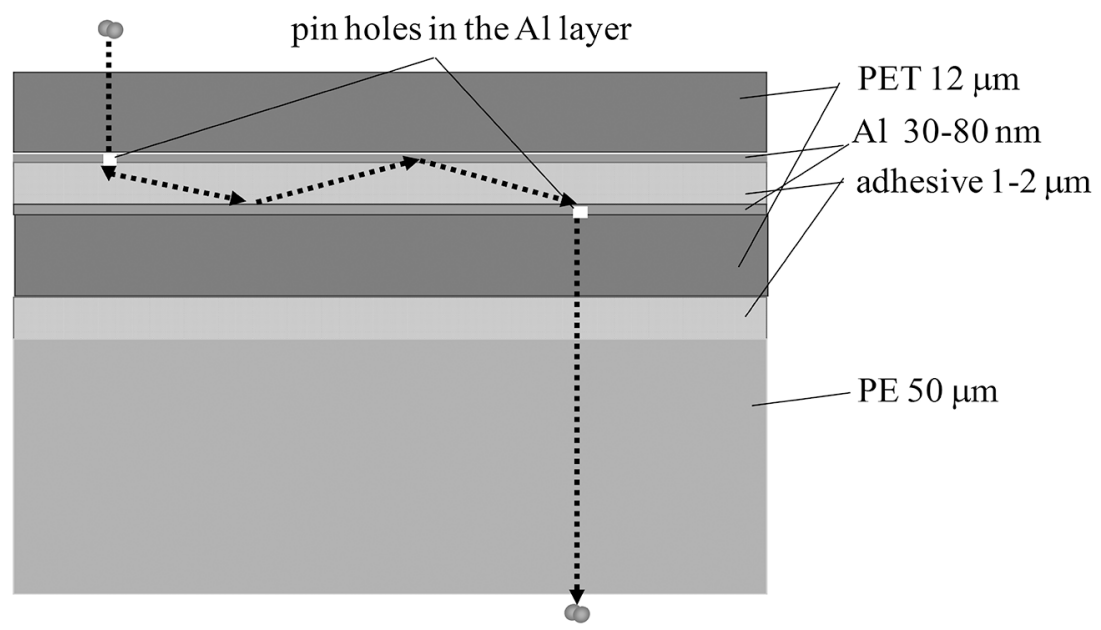

Fig. 5. - Construction of a high-barrier laminate for a VIP.

only at a gas pressure of about 100 mbar a significant increase could be recognised. This is a safety margin of 100 mbar considering a typical gas pressure increase of 1 mbar per year by penetrating nitrogen and water molecules through the high barrier laminate and the sealing rims.

In fig. 5 a typical design of a high-barrier laminate used for VIP is depicted. The polyethylene $(\mathrm{PE})$ layer is necessary to enable the thermal welding of the laminate at VIP rims. The aluminium ( $\mathrm{Al}$ ) layers work as barrier layers against penetrating air gas molecules, e.g. nitrogen, oxygen and water vapour. It is important to use more than one thin $\mathrm{Al}$ layer in the range of several nanometers, e.g. two or three, to reduce thermal heat transfer via these layers and therefore a thermal bridge at the VIP rims. The minimum thickness of the adhesive layer embedded between the two metal layers is also important. If pin holes, i.e. defects which could not be avoided, occur in the Al layers the penetrating gas molecules have to diffuse parallel to the pressure gradient until they hit upon a further pin hole in the next Al layer.

A second possibility to reduce the total thermal conductivity of an insulation material is to reduce the pore size to such an amount that the mean free path of the gas molecules is reduced. This is the case for microporous materials. Typical microporous materials used for thermal insulation in building applications are silica aerogels [5,6], pyrogenic silica, i.e. fumed silica and precipitated silica and mixtures and blends from those. Since the pure materials are fragile and brittle, often blends with fibres are used to enhance the mechanical stabilityin products. Additionally also infrared opacifier are added to reduce the heat transfer by thermal radiation. A picture of silica aerogel as monolith and granulate is shown in fig. 6. Monolithic silica aerogel is a material which shows one of the lowest thermal conductivity values of the world at ambient conditions, which could be in the range of $0.010 \mathrm{Wm}^{-1} \mathrm{~K}^{-1}$. In comparison to this value the effective total 


\section{EPJ Web of Conferences}

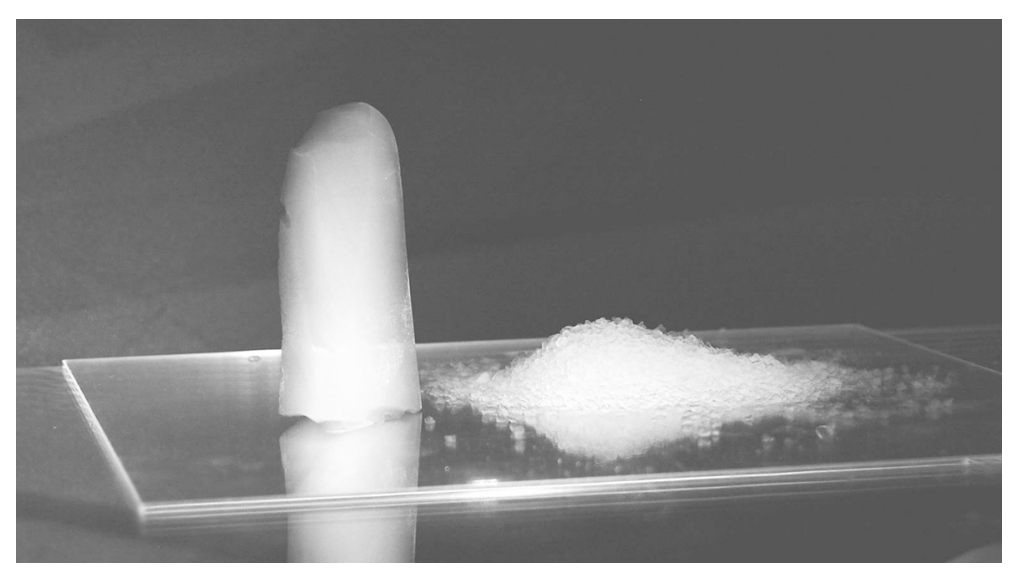

Fig. 6. - Monolithic silica aerogel (on the left side) and silica aerogel granulate (right side).

thermal conductivity increases for silica aerogel powder to about $0.013 \mathrm{Wm}^{-1} \mathrm{~K}^{-1}$ and above $0.02 \mathrm{Wm}^{-1} \mathrm{~K}^{-1}$ for silica aerogel granulate, because more and more large pores between the particles increase the contribution of the pore gas.

\section{2. - Vacuum insulation glass (VIG)}

The walls of modern well insulated buildings nowadays can reach $U$-values of $<$ $0.2 \mathrm{Wm}^{-2} \mathrm{~K}^{-1}$. Today, the remaining thermal leaks in the façade of these buildings are glazings with typical $U$-values of about $1.0 \mathrm{Wm}^{-2} \mathrm{~K}^{-1}$. One attractive possibility to essentially improve the insulation properties of a glazing is to suppress the heat transport due to conduction and convection of the filling gas by evacuating the space between the glass panes (cf. fig. 7).

Funded by the German Federal Ministry of Economics and Technology within several R\&D projects a consortium of partners from industry and research institutes was established to investigate the feasibility of producing a vacuum insulation glazing with outstanding thermal resistance [7]. In a vacuum insulation glazing two glass panes, connected by an airtight edge seal, are evacuated to a pressure of about $10^{-4}$ mbar. One pane is coated with an infrared-reflecting, low-emissivity layer (emissivity $\approx 0.03$ ) to minimize thermal transport between the panes. A matrix of spacers is necessary to handle the mechanical load lasting on the glass panes due to the atmospheric pressure and prevent them from collapsing.

Actually new sealing techniques are developed which allow for lower fabrication temperatures and thus enable the implementation of highly efficient low-emissivity coatings. These sealing techniques include the soldering of metal foils onto the glass panes and the subsequent welding of the foils in a vacuum chamber forming the needed airtight edge seal. First samples have already been constructed and the mechanical stability as well as the tightness of the edge seal is very promising. 


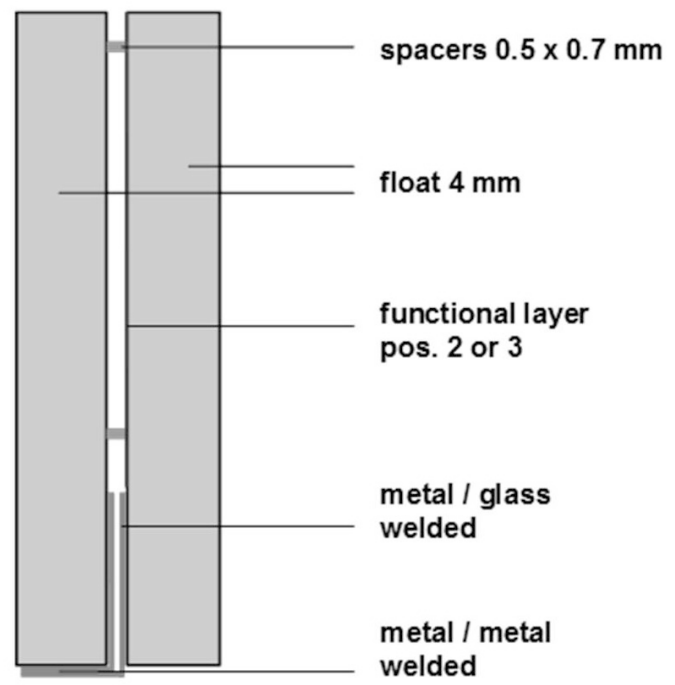

Fig. 7. - Principle of a Vacuum Insulation Glass construction.

\section{3. - Integrated research for energy-efficient buildings}

In 2010 ZAE Bayern started the realization of the research and demonstration building "Energy Efficiency Center" (EEC) in Würzburg, Germany (cf. fig. 8). The EEC comprehends the innovative know-how from the involved research partners from science and industry in order to share experience and exchange ideas [8]. From the very beginning of the project an interdisciplinary project team, consisting of researchers from the ZAE Bayern, architects and engineers developed the building concept and new approaches to integrate innovative technologies in a general concept. The main objectives were the implementation of energy-efficient cutting-edge technologies, the optimization of their interaction for maximum energy efficiency, and the demonstration. The involved innovative technological approaches are lightweight highly insulating facades (with translucent aerogel modules, vacuum insulations, low-e coatings), textile roof construction (light and climate management), innovative low exergy heating, cooling and air conditioning technology with implemented heat and cold storage systems (PCM components, passive infrared radiation cooling and open adsorption cooling technology), innovative daylighting and artificial lighting systems and an adaptive high-level control system, which ensures the most efficient interaction of the smart building technologies with changing environmental influences. Many of these technologies were investigated within the research initiative EnOB (Research for energy-optimized construction) of the German Federal Ministry of Economics and Technology (BMWi). A research server which is part of the high-level control system enables the conduction of experiments with the implemented building components of the EEC and manages the data acquisition. The combination of research, demonstration and dissemination of knowledge in one place will generate the necessary boost for the 


\section{EPJ Web of Conferences}

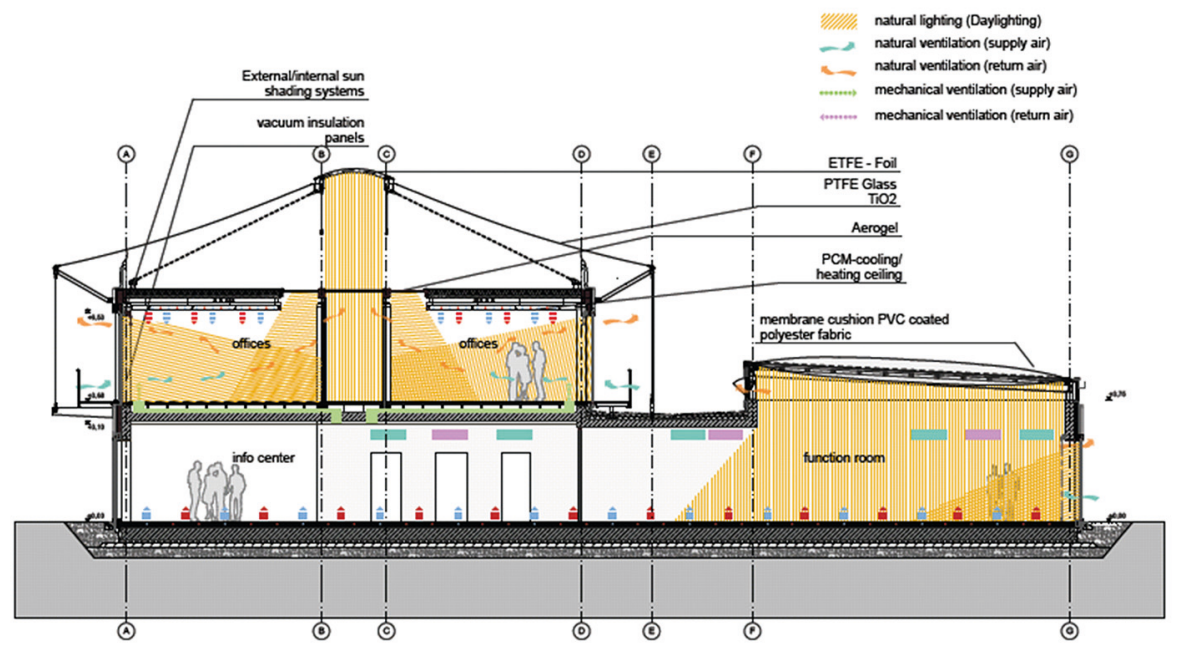

Fig. 8. - Cross-section of the EEC showing the daylight distribution with in the building by means of the translucent and transparent membranes.

fast implementation of energy-efficient technologies in the building sector. Therefore the EEC is a highly dynamic innovation driver and this approach has the potential to achieve maximum market impact and public visibility and accelerate innovation processes.

3`1. Membranes and lightweight construction. - The Energy Efficiency Center manifests its strict orientation towards sustainability and energy avoidance not only during its life cycle, but already with the choice of structure type and construction method applied to erect the building. The design parameters of intensive use of solar effects and especially the utilization of lightweight materials and weight-saving construction methods became the building's central ideas. The significant reduction of primary energy used to produce, transport and install the lightweight elements of the building shell, the load-bearing structure and the lightweight structures at the inside of around $1 / 3$ compared to similar constructions of more rigid design (except wood constructions) serves as important basis for the building's entire efficiency concept. The low-mass construction elements are influenced by applying specific coatings and substance additions to optimize the desired characteristics such as heat capacity and behaviour towards thermal radiation. Examples are the use of titanium dioxide and low-e coatings as well as of so-called phase-change materials (PCM).

The EEC's roof is the most significant architectural particularity in terms of lightweight construction of the building and emphasizes its distinctive character. In addition to design and structural characteristics, inherent to roof skins made of textile construction materials, physical and energetic features are the most prominent in the case of the EEC, which characterize the use of membranes and foils as part of a multishell roof construction. The optimization of individual functions at each level of the 
multi-layer building shell together with the generation of additional effects in the intermediate layers leads to synergetic effects, which is why multi-layer design is implemented in general. This fundamental approach fits well with the philosophy of consistently using lightweight materials. Each shell layer takes on its intended function for which it is especially selected and optimized.

The textile construction materials fulfil as frame structure the general structural function of the self-supporting roof as well as of a weather protection against wind, rain and snow. Moreover, they form the external boundary of the intermediate zone that either acts as thermally preconditioned heat-insulating layer or, in the summer, is ventilated to avoid overheating. The fundamental difference of textile construction material compared to mostly bending-stiff, hard materials is their per se translucent or transparent property. Unlike glass or transparent/translucent panel-type materials, textile surfaces under tensile and compressive stresses can be stabilised without heavy and detailed substructures thus reducing material use for the membrane structures even more.

The heat-insulating layer is provided by different material combinations made of hard panel-type materials depending on the required features and the installation situation. In combination with light-transmission properties of the textile materials on top, the amount of light and thermal radiation transmitted, reflected and absorbed was precisely adjusted. High-performance insulation materials such as the extremely light aerogel contribute to the consistent implementation of the lightweight construction principal.

Exploiting light transmission is of fundamental importance for energy savings during operation of the building. Whereas in residential buildings the energy need mainly consists of heat production in form of heating energy and warm water, in office buildings the energy supply for artificial lighting plays an important role. The creation of translucent ceilings above the underlaying zones of the offices and the interior corridors, which do not benefit from the natural lighting through the facade, improves the daylight autonomy up to $100 \%$ in some building areas.

3·2. Integrated smart technology. - The approach of a lightweight construction in combination with a highly insulating envelope has to be coupled with measures to enhance the thermal mass of the building to avoid extensive cooling/heating loads and control technologies. Therefore, in the EEC different thermal storage systems are integrated. The applied low-exergy heating and cooling systems work with low temperature differences at a minimum temperature level. To provide the cooling for the regeneration of the building-integrated phase change materials (PCM) in a very energy-efficient way, the ZAE-developed "Passive Infrared Night Cooling"-system (PINC) is connected to one of the firefighting water tanks. To support the passive cooling/heating of the PCM-ceilings, a new developed Liquid Desiccant Cooling system (L-DCS) provides cool or preheated, dehumidified air to the offices. These three innovative technologies and their interaction are described beneath.

The EEC has two firefighting water tanks with a volume of $100 \mathrm{~m}^{3}$ each, which are also used as cold water thermal energy storage (TES). They are both connected to the buildings water cooling circuits by means of heat exchangers. One tank is cooled by 


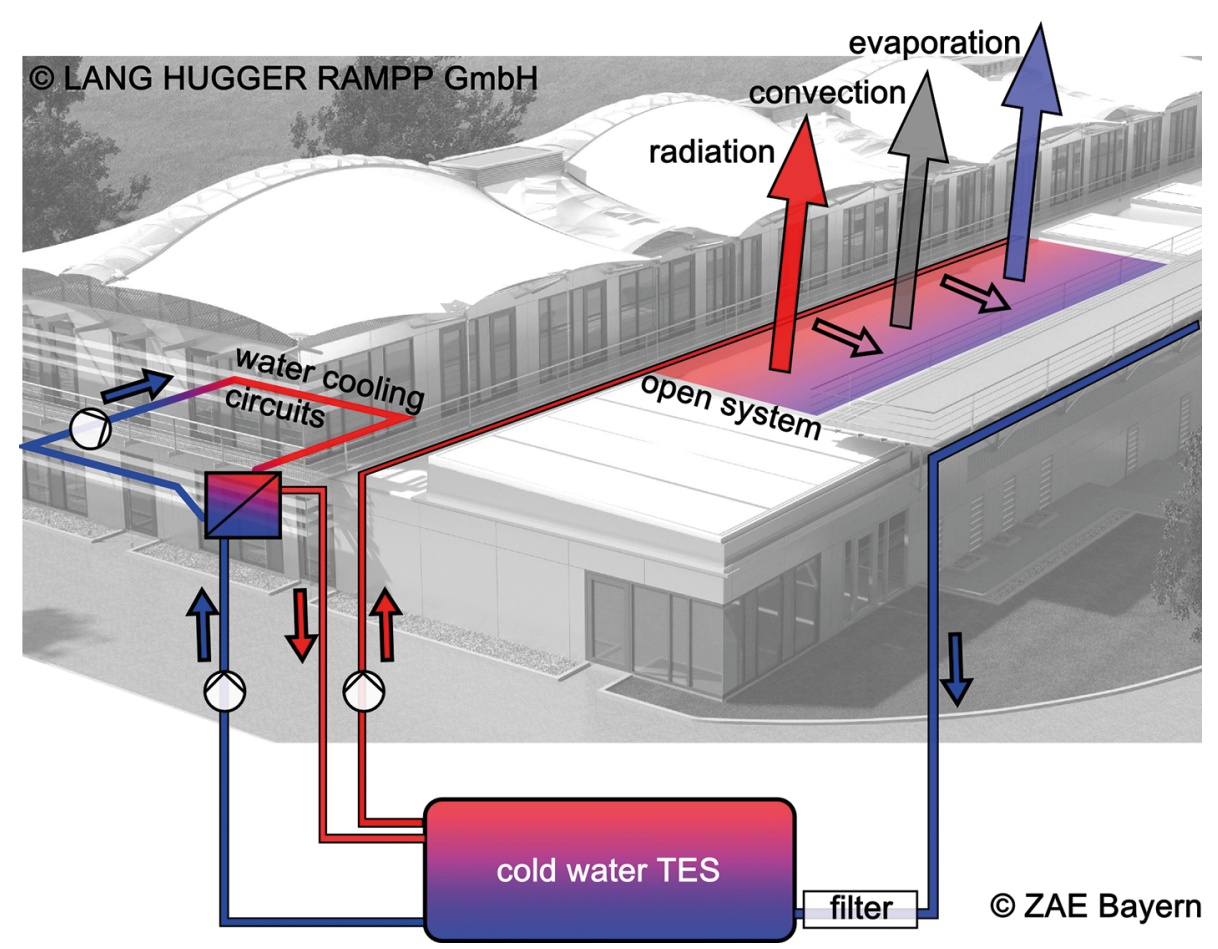

Fig. 9. - The cooling load is connected to the TES by means of a heat exchanger. The water in the TES is re-cooled on the rooftop, mainly during nighttime. Heat is released from the water flowing upon the roof surface by infrared radiation as well as by convection and evaporation.

a conventional compression cooler, the second one is connected to the ZAE-developed PINC, which supplies the needed cold. A scheme of this system can be found in fig. 9 .

This very efficient cooling method is successfully in operation in the existing ZAE building in Würzburg since 2000: heat from laboratories (appliance cooling) and offices (PCM cooling ceilings) is transferred into the TES by means of a heat exchanger. In order to re-cool the TES, the contained water is pumped onto a seperate area of the rooftop during nighttime. Since it is a hydraulically open system, the water runs freely over the slightly sloped rooftop surface and ideally cools down to dew-point temperature.

That means there is a strong dependence between the cooling power density and the water temperature. Thus higher water temperatures lead to a higher cooling power density. Assuming typical water temperatures of about $18^{\circ} \mathrm{C}$ and the climate conditions in Würzburg, which is located in the southern part of Germany, a cooling power density of around $60-120 \mathrm{Wm}^{-2}$ roof area can be achieved even in summer nights.

The cooled water flows through rain pipes and a filter and is again collected in the cold water TES. Electricity is only needed to transport the water, so a high COP $(>20)$ can be achieved. The cooling cycle typically lasts about 8 hours and yields a reservoir temperature of around $13-18^{\circ} \mathrm{C}$. 


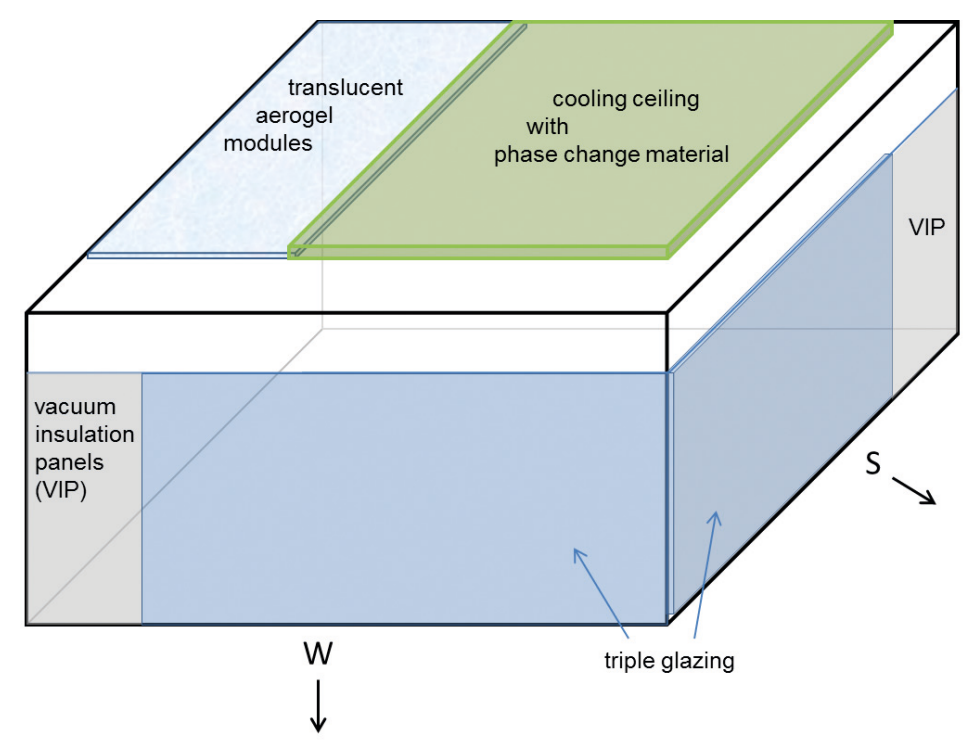

Fig. 10. - Simulation model of the south-west-oriented office.

As PINC is an open system, water evaporates and the loss has to be compensated which is automatically achieved by additionally collecting rain water.

3.3. PCM systems. - Due to its lightweight structure, the translucent building envelope, and the high internal gains, the EEC has an increased heat load. To prevent an excessive temperature rise on warm and sunny days, phase change materials (PCM) with a high thermal storage capacity are integrated into the newly developed cooling ceiling construction as well as into the wallboards. The PCM undergoes a reversible phase change between the solid and the liquid state at a temperature of about $23^{\circ} \mathrm{C}$. During phase transition a PCM can store a large amount of heat within a narrow temperature range as all absorbed heat is required to break up the bonds of the crystal lattice. With the PCM in thermal contact with the room air this leads to a temperature stabilization effect, so temperature peaks are cut off. The passive temperature stabilization effect supports the office-cooling, so no active cooling is needed most of the year. To ensure the thermal effect of the PCM, it is necessary to solidify (i.e. regenerate) the material during the night. The regeneration of the PCM in the cooling ceilings is realized by a cooling circuit connected to the firefighting water tank. As the water in the tank is mainly cooled by "Passive Infrared Night Cooling" this is a very energy-efficient system. The regeneration of the PCM in the wallboards is achieved by convection.

To predict the thermal effect of the ceiling-implemented PCM, a thermal building simulation was carried out. A detailed model of the south-west-oriented office was implemented which is shown in fig. 10. The transparent façade areas are triple glazed; in the opaque elements vacuum insulation panels are integrated. Therefore a high thermal 


\section{EPJ Web of Conferences}

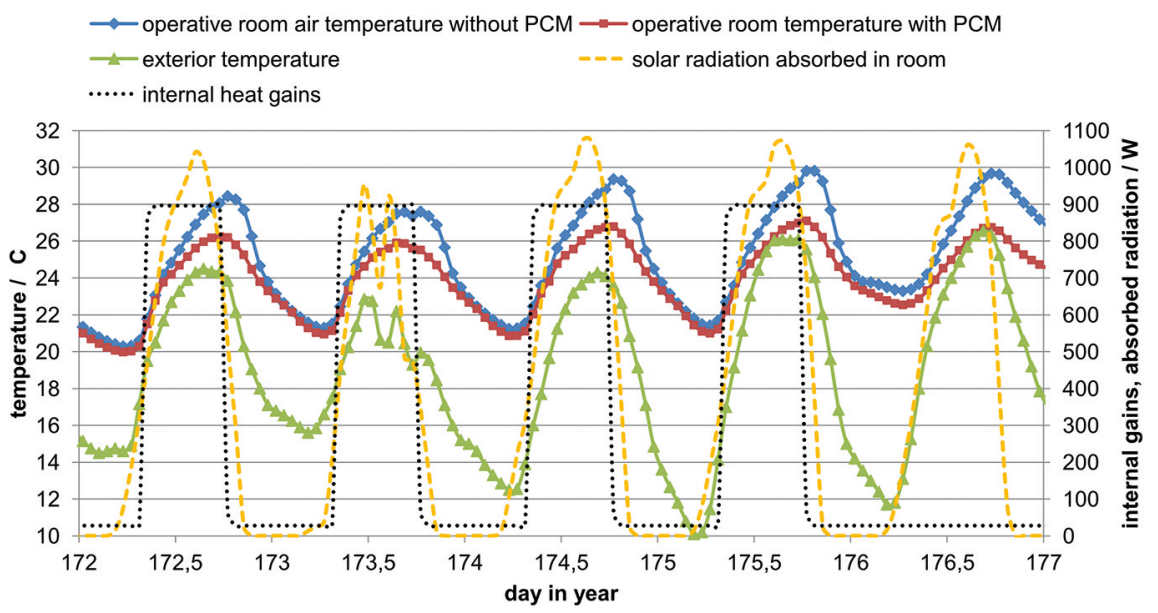

Fig. 11. - Operative temperatures in the room with and without PCM in the cooling ceiling. Additionally, the exterior temperature, the solar heat gains, and the internal heat gains are shown.

insulation is achieved by a thin wall construction. The highly insulating but translucent aerogel-module which is, in combination with the translucent membrane rooftop, providing natural lighting for the office, is also represented in the simulation model. The cooling ceiling with an active area of $21 \mathrm{~m}^{2}$ is equipped with 90 modules of macro-encapsulated salt-hydrate PCM with a mass of about $180 \mathrm{~kg}$ and a surface of $12.4 \mathrm{~m}^{2}$. The inner walls are constructed of gypsum boards and insulation material.

The simulation was run using the test reference year weather data set for Würzburg, Germany, with extreme summer conditions (TRY-Region 13 [9]).

As can be seen in fig. 11, there are high solar gains during the simulated days. The solar heat gains together with internal heat gains caused by electronic devices and the employees lead to a rise in operative temperature above outdoor temperature. When comparing the operative temperature curves of the room with and without PCM in the ceiling, differences in the thermal behavior of the room become obvious. Due to the good thermal insulation of the building envelope and the low thermal mass of the building, the rise in operative room temperature is significantly higher for the case "no PCM" than for the case "with PCM". The PCM is able to dampen temperature fluctuations by storing heat during the phase transition. During the working time from 8 am to $6 \mathrm{pm}$ the temperature "with PCM" rarely exceeds $26^{\circ} \mathrm{C}$, so in most cases the temperature stays in the comfort range and no additional active cooling is required.

Active regeneration is required to reliably solidify the PCM. The simulation shows that the PCM can be completely regenerated with cold water of $18^{\circ} \mathrm{C}$ during a regeneration period between $9 \mathrm{pm}$ and $6 \mathrm{am}$ (see fig. 12). To reduce energy consumption, no active regeneration is provided during the weekend (see, e.g., day 176 in fig. 12). 


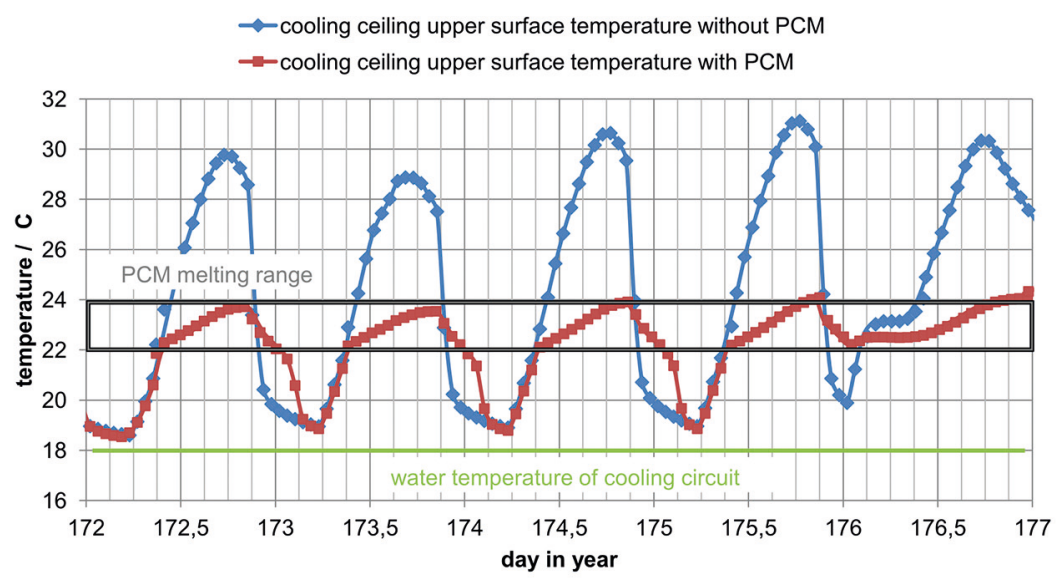

Fig. 12. - Temperature of the upper side of the cooling ceiling (PCM-temperature for the case "with PCM").

In the EEC, the regeneration of the PCM will additionally be controlled by the buildings high-level control system. The control system uses a local weather forecast to ensure a demand-based regeneration of the PCM. If the weather forecast predicts a period of cold days for example, the PCM will not be regenerated actively in order to further reduce the energy consumption.

3*4. Concept of the building automation and monitoring. - The building automation should enable an effective and efficient control of the installed HVAC (heating, ventilation and air conditioning), sun protection and lighting systems. It is essential to receive by means of the building automation system a maximum of efficiency in respect of energy consumption and operating costs. In addition to the state-of-the-art building control system an additional high-level controller is implemented. Therefore scientists are able to have full control over the automation and data acquisition system and to use the EEC as a huge experimental set up.

Since the EEC was put into full operation in spring 2014, an intense monitoring process started. Concerning the PCM systems, eight special test rooms are equipped with different PCM-ceiling and wallboard systems. Four of the test rooms are situated on the southern side of the building, four rooms on the northern side. On both sides one test room functions as reference and does not contain any PCM. This setup enables a very dense data acquisition and a detailed analysis of the system's performance. In the future weather and occupancy forecasts will be implemented for an optimal control of the thermal storage systems (PCM and PINC) of the building. 


\section{EPJ Web of Conferences}

\section{4. - Conclusions and outlook}

The further improvement of energy efficiency plays a vital role for our future energy systems. The fact that $40 \%$ of the European energy consumption belongs to the building sector underlines the importance of $\mathrm{R} \& \mathrm{D}$ works in this field. It is important to recognize that in general a building with all its aspects, i.e. envelope, construction, building technology and automation, has to be understood as a unit, and interdisciplinary planning and research work on materials, components and systems is essential to realize the highly-energy-efficient building of the future.

$$
* * *
$$

The Energy Efficiency Center was supported by the German Federal Ministry of Economics and Technology because of a decision of the German Bundestag and the Federal state of Bavaria.

\section{REFERENCES}

[1] Ebert H. P., "Thermal Properties of Aerogels", in Aerogels Handbook, edited by Aegerter M. A., Leventis N. and Koebel M., 1st edition (Springer) 2011.

[2] Fricke J., From Dewars to VIPs - One Century of Progress in Vacuum Insulation Technology in 7th International Vacuum Insulation Symposium. Zürich-Dübendorf (2005).

[3] Baetens R., Jelle B. R. P., Thue J. V., Tenpierik M. J., Grynning S., Uvslakk S. and Gustavsen A., Energy Buildings, 42 (2010) 147.

[4] Fricke J., Heinemann U. and Ebert H.-P., Vacuum, 82 (2008) 680.

[5] Aegerter M. A., Leventis N. and Koebel M. M. (Editors), Aerogels Handbook (Springer Science+Business Media, New York) 2011.

[6] Fricke J., Aerogels Sci. Am., 256 (1988) 92.

[7] Fricke J., Ebert H.-P., Vidi S., Heinemann U., Weinläder H., Reichenauer G. and Geisler M., "Optimized Materials and Novel Concepts for Highly Efficient Insulants", in Thermal Conductivity, edited by GaAl D. S., GaAl P. S., Vol. 30 (DESTech Publications, Inc., Pittsburgh, PA) 2009.

[8] Rampp T., Klinker F., Ebert H.-P., Körner W., Weismann S., Büttner D., Weinläder H. and Mehling H., "The Energy Efficiency Center: Lightweight Construction With Smart Technology", in Proceedings of the SB13munic, München, 24-26 April 2013 (Fraunhofer IRB Verlag) 2013.

[9] Christoffer J., Deutschländer T. and Webs M., "Testreferenzjahre von Deutschland für mittlere und extreme Witterungsverhältnisse TRY", in Selbstverlag Deutscher Wetterdienst (Offenbach) 2004. 